\title{
Human health risk assessment: Models for predicting the effective exposure duration of on-site receptors exposed to contaminated groundwater
}

\author{
Renato Baciocchi ${ }^{a}, *$, Simona Berardi ${ }^{b}$, Iason Verginelli ${ }^{a}$ \\ a Department of Civil Engineering, University of Rome “Tor Vergata", Via del Politecnico, 1, 00133 Rome, Italy \\ ${ }^{\mathrm{b}}$ Department of Production Plants and Anthropic Settlements (DIPIA) - National Institute for Prevention and Safety at Work (ISPESL), Via Urbana, 167, 00184 Rome, Italy
}

\section{A R T I C L E I N F O}

\section{Article history:}

Received 21 July 2009

Received in revised form 30 March 2010

Accepted 4 May 2010

Available online 8 May 2010

\section{Keywords:}

Contaminated sites

Risk analysis

Fate and transport

Exposure duration

On-site receptors

Depleting source

\begin{abstract}
A B S T R A C T
Clean-up of contaminated sites is usually based on a risk-based approach for the definition of the remediation goals, which relies on the well known ASTM-RBCA standard procedure. In this procedure, migration of contaminants is described through simple analytical models and the source contaminants' concentration is supposed to be constant throughout the entire exposure period, i.e. 25-30 years. The latter assumption may often result over-protective of human health, leading to unrealistically low remediation goals. The aim of this work is to propose an alternative model taking in account the source depletion, while keeping the original simplicity and analytical form of the ASTM-RBCA approach. The results obtained by the application of this model are compared with those provided by the traditional ASTM-RBCA approach, by a model based on the source depletion algorithm of the RBCA ToolKit software and by a numerical model, allowing to assess its feasibility for inclusion in risk analysis procedures. The results discussed in this work are limited to on-site exposure to contaminated water by ingestion, but the approach proposed can be extended to other exposure pathways.
\end{abstract}

(c) 2010 Elsevier B.V. All rights reserved.

\section{Introduction}

The management of contaminated sites is often based on a risk-based approach, where the actual pollution of the site is evaluated depending on the effective risk posed to the human health of exposed receptors. This approach is based on the information collected during the contaminated site investigation, which are used to evaluate the potential effects on the health of exposed receptors, allowing to assess whether a particular site requires remedial action and eventually the specific risk-based remediation goal $[1,2]$.

The most acknowledged technical and scientific references for this approach are the ASTM Risk Based Corrective Action (RBCA) standards for evaluating petroleum sites (E 1739-95) and chemical release sites (E 2081-00) [3,4]. The procedure outlined in these documents is based on a tiered approach for the management of contaminated sites, with increasing complexity in the definition of the site conceptual model and in the description of the physical and chemical phenomena underlying the fate and transport of contaminants. In Tier 1, aimed to the definition of the contamination screening values, only on-site receptors are considered, transport of contaminants is described through simple analytical

\footnotetext{
* Corresponding author.

E-mail addresses: baciocchi@ing.uniroma2.it (R. Baciocchi), simona.berardi@ispesl.it (S. Berardi), verginelli@ing.uniroma2.it (I. Verginelli).
}

models and conservative default values are used for all hydrogeological, geometrical and exposure data, without requiring any site characterization. In Tier 2, aimed to evaluate site-specific target levels, off-site receptors are included in the conceptual model, all input data should possibly be site-specific, whereas models used to describe contaminants' transport are still analytical. Usually, the risk analysis procedure is performed using the Tier 2 conditions, that represent a reasonable compromise between the need for a detailed site assessment and the advantage of handling a rather simple and easy-to-use management tool. Therefore, only in very specific situations, where a more detailed description of the contaminant transport through numerical models is required, risk analysis is performed following the Tier 3 approach.

Among the different simplifying assumption of Tier 2 models, a key one consists in considering a constant concentration value for the contamination source throughout the entire exposure period of a generic receptor. This approach is somehow mitigated in the case of vapor volatilization from soil, by introducing a limit on the maximum amount of contaminant that can be generated by the contamination source, whereas no mention to this issue is given in the ASTM-RBCA guidelines for contamination source in groundwater, neither for volatilization, nor for migration in the saturated zone. This assumption may lead, for some types of constituents and soils, to extremely conservative results in terms of risk as the source reduction due to the various attenuation processes may occur and have a significant influence on contaminant 


\begin{tabular}{|c|c|}
\hline \multicolumn{2}{|c|}{ Nomenclature } \\
\hline$C_{0}$ & initial concentration $(\mathrm{mg} / \mathrm{L})$ \\
\hline$C_{\text {poe }}$ & concentration at point of exposure $(\mathrm{mg} / \mathrm{L})$ \\
\hline$C_{\mathrm{w}}$ & concentration in liquid phase $\left(\mathrm{g} / \mathrm{m}^{3}\right)$ \\
\hline E & $\begin{array}{l}\text { daily chronic contaminant exposure rate } \\
(\mathrm{mg} /(\mathrm{kg} \times \text { day }))\end{array}$ \\
\hline ED & exposure duration (years) \\
\hline $\mathrm{ED}_{\text {eff }}$ & average exposure duration (years) \\
\hline$f_{\mathrm{oc}}$ & mass fraction of organic carbon $(\mathrm{g} / \mathrm{g})$ \\
\hline HQ & hazard quotient $(-)$ \\
\hline$i$ & groundwater gradient $(\mathrm{m} / \mathrm{m})$ \\
\hline$K_{\mathrm{d}}$ & soil/water partition coefficient $(\mathrm{L} / \mathrm{kg})$ \\
\hline$K_{\mathrm{d}}^{*}$ & limit soil/water partition coefficient $(\mathrm{L} / \mathrm{kg})$ \\
\hline$K_{\mathrm{oc}}$ & organic carbon/water partition coefficient $(\mathrm{mL} / \mathrm{g})$ \\
\hline$K_{\mathrm{s}}$ & saturated hydraulic conductivity $(\mathrm{cm} / \mathrm{s})$ \\
\hline$M_{\mathrm{S}}$ & mass in soil sorbed phase (kg) \\
\hline$M_{\text {tot }}$ & total mass initially present $(\mathrm{kg})$ \\
\hline$M_{\text {transp }}$ & mass transported $(\mathrm{kg})$ \\
\hline$M_{\mathrm{w}}$ & mass in dissolved phase $(\mathrm{kg})$ \\
\hline$Q$ & groundwater flow $\left(\mathrm{m}^{3} / \mathrm{s}\right)$ \\
\hline$R$ & lifetime cancer risk $(-)$ \\
\hline RfD & reference dose $(\mathrm{mg} /(\mathrm{kg} \times$ day $))$ \\
\hline$S_{\mathrm{d}}$ & thickness of source-zone area $(\mathrm{cm})$ \\
\hline SF & slope factor $(1 /[\mathrm{mg} /(\mathrm{kg} \times$ day $)])$ \\
\hline SSTL & site-specific target level (mg/kg or $\mathrm{mg} / \mathrm{L}$ ) \\
\hline$S_{\mathrm{w}}$ & $\begin{array}{l}\text { length of source-zone area parallel to groundwater } \\
\text { flow }(\mathrm{cm})\end{array}$ \\
\hline$t$ & time (years) \\
\hline$U_{\mathrm{gw}}$ & ground water Darcy velocity (cm/day) \\
\hline$V$ & source volume $\left(\mathrm{m}^{3}\right)$ \\
\hline$W_{\mathrm{gw}}$ & width of source-zone area $(\mathrm{cm})$ \\
\hline & soil porosity $\left(\mathrm{cm}^{3} / \mathrm{cm}^{3}\right)$ \\
\hline$\rho_{\mathrm{s}}$ & dry soil bulk density $\left(\mathrm{g} / \mathrm{cm}^{3}\right)$ \\
\hline
\end{tabular}

concentrations. As a matter of fact, several studies have shown that natural attenuation (NA) can be particularly effective in reducing the mass, toxicity, mobility, volume and concentrations of contaminants [5-9]. NA refers to naturally occurring processes in soil and groundwater environments that act without human intervention [10]. These natural processes include biological degradation, volatilization, dispersion, dilution, and sorption of the contaminant onto the organic matter and clay minerals in the soil [11]. Recent studies have demonstrated the occurrence of natural attenuation by studying the evolution of the plume length [12-14], the mass reduction [15], the geochemical processes [16] and the vertical profile of vapors [17-19]. Various commercial packages are available for simulating these processes. The analytical models BIOSCREEN [20] and BIOCHLOR [21] allow to simulate the NA for petroleum fuel and chlorinated solvents, respectively. The Domenico analytical transport model [22] is the basis for these models and includes the assumption that the source concentration does not change with time. On the other hand, the RBCA ToolKit [23] and the RISC 4 [24] packages account for the decrease in exposure concentration due to volatilization, biodegradation and leaching for contaminated soil and due to dissolution and biodegradation in the case of groundwater source. In addition numerical models such as BIOPLUME III 2-D [25], MODFLOW [26] coupled with RT3D [27] and FEFLOW [28] allow to simulate this process.

It is worth noting that all these models simulate a transient condition and thus the risk is not calculated using the usual equations of a Tier 2 framework but rather as the sum of the incremental risk values associated to each exposure interval.
Hence in this paper a model to overcome the limitation of the ASTM-RBCA one, but keeping its original simplicity (Tier 2 framework), was developed. This model accounts for source attenuation, through a simple material balance, identifying the time required for depletion and consequently the effective exposure duration. The only source attenuation mechanism included in this work relies on run-off by groundwater flow, which is assumed to be dominant with respect to volatilization. Although biodegradation may some times contribute significantly to source depletion, it is not considered here, since it would require a level of characterization, that is usually not available when performing a Tier 2 risk analysis. The results provided by the proposed model are then compared with those obtained through the traditional ASTM-RBCA approach, a model based on the source depletion algorithm of the RBCA ToolKit software and a commercial numerical model (FEFLOW), allowing to assess its feasibility for inclusion in risk analysis procedures.

\section{Modelling}

The risk for human health correlated to the exposure to a given contaminant, may be calculated applying the following general equation:

$R=E \cdot T$

where $T$ is the contaminant toxicity. The individual risk is defined as the risk for human health associated to a specific exposure route and to a single contaminant. Its determination is performed in a different way, depending on the type of contaminant's effects (carcinogenic or toxic), that the given compound may have on the human health receptor [29]. Namely, in the case of carcinogenic compounds:

$R=E \cdot \mathrm{SF}$

where $R$ is the life-long probability of incremental cancer case occurrence, caused by exposure to the contaminant, SF (slope factor) is the probability of incremental cancer case occurrence per unit dose, $E$ is the exposure, averaged to a lifetime exposure duration (AT $=70$ years).

For toxic, non-carcinogenic effects:

$\mathrm{HQ}=\frac{E}{\mathrm{RfD}}$

where HQ is the so-called "Hazard Quotient", defined as the ratio between the actual exposure to a given contaminant and the corresponding maximum allowable or reference dose, RfD (Reference Dose), i.e. the daily exposure rate that does not induce adverse effects on humans during the entire life-time; and $E$ is the daily chronic contaminant exposure rate. The latter one is the product of the contaminant's concentration at the point of exposure, $C_{\text {poe, }}$, with the effective exposure rate, EM, that may correspond to the daily ingested soil amount, inhaled air volume or ingested water volume, per unit body weight, depending on the exposure pathway considered:

$E=\mathrm{EM} \cdot C_{\text {poe }}$

The estimation of the effective exposure rate requires evaluating the daily dose of the contaminated matrix that is assumed by the human receptors identified in the conceptual model [30].

The effective exposure rate, EM, depends on the ingestion or inhalation rate, $\mathrm{CR}$, the exposure frequency, $\mathrm{EF}$, the exposure duration, ED, the body weight, BW, and the averaging time, AT. The general form of the equation used to estimate this parameter is as follows:

$\mathrm{EM}=\frac{\mathrm{CR} \cdot \mathrm{EF} \cdot \mathrm{ED}}{\mathrm{BW} \cdot \mathrm{AT}}$ 
The concentration at the point of exposure, $C_{\text {poe, }}$, is estimated introducing the appropriate transport factor, FT:

$C_{\text {poe }}=\mathrm{FT} \cdot C_{\mathrm{s}}$

The transport factor, FT, accounts for the physical and chemical properties of the contaminant, the mechanism of the contaminant's release to the different environmental compartments, the physical and chemical properties of the environmental matrix through which migration occurs and the interactions between the contaminant and the matrix along the migration pathway [31].

In this framework, the analytical fate and transport models included in the ASTM-RBCA standard are based on the following assumptions [32]:

- constant source concentration;

- fixed exposure duration (for instance for industrial receptors, $\mathrm{ED}=25$ years).

This assumption, which relies on considering a time-independent source-area concentration, may often result in too conservative results, since the groundwater flow usually and actually leads to a gradual run-off of the source concentration until its complete depletion. The main parameters that influence the source run-off are the site hydro-geological characteristics (e.g., hydraulic gradient and soil texture) and the contaminant's properties (e.g., partition coefficient). This means that in practice, also the exposure duration will not be fixed, but will depend on the time required for the complete source depletion.

Since the model proposed by the ASTM-RBCA standard is not suitable for describing these effects, two alternative analytical models are described in this work that take into account source depletion:

(1) a simple model, developed by us, based on the same equation given above for risk calculation, but which accounts for source depletion using a material balance approach to evaluate the period of exposure, assuming constant source concentration until complete depletion by groundwater run-off;

(2) a model based on the source depletion algorithm included in RBCA ToolKit [23], assuming variable concentration over time. In this case the total risk is calculated as the sum of the incremental risk values associated to each exposure interval.

The derivation of both analytical models is described in the following section, which is followed by a section where the details of the numerical model used for comparison are summarized.

\subsection{Analytical models}

\subsubsection{Exposure-Duration model}

Let us assume the conceptual model shown in Fig. 1 with a contamination source located in the aquifer (contaminated groundwater).

Assuming that no NAPL is present, the contaminant's total mass $M_{\text {tot }}$ (Eq. (7)), can be expressed as the sum of the mass in the dissolved phase $M_{\mathrm{w}}$ (Eq. (8)) and the mass in the soil sorbed one $M_{\mathrm{S}}$ (Eq. (9)):

$M_{\mathrm{tot}}=M_{\mathrm{w}}+M_{\mathrm{S}}$

$M_{\mathrm{w}}=V \cdot C_{\mathrm{w}} \cdot \theta_{\mathrm{e}}$

$M_{\mathrm{S}}=V \cdot \rho_{\mathrm{s}} \cdot C_{\mathrm{S}} \cdot\left(1-\theta_{\mathrm{e}}\right)$

where $V$ is the total source volume, $C_{\mathrm{w}}$ and $C_{\mathrm{s}}$ are the average source concentration in water and soil, respectively, and $\theta_{\mathrm{e}}$ is the effective soil porosity.

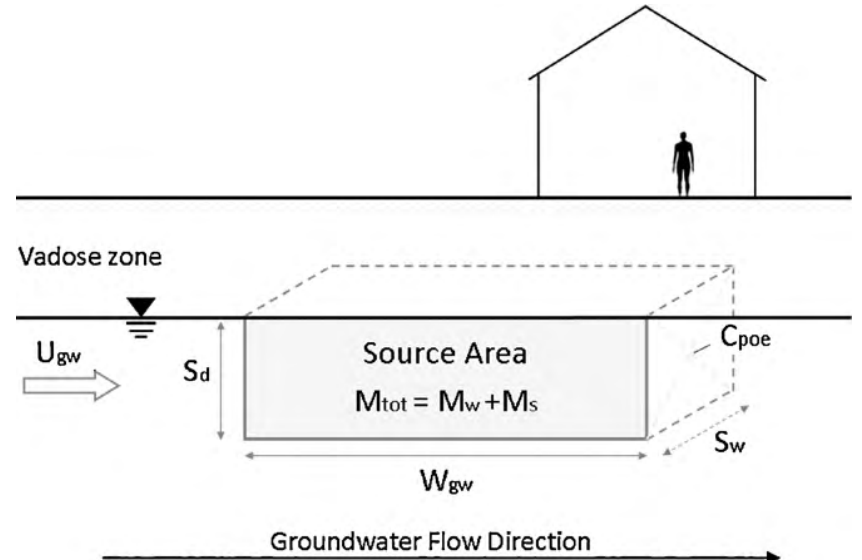

Fig. 1. Conceptual model.

The concentration in the soil sorbed phase can be expressed, assuming a linear equilibrium, in terms of the concentration in the dissolved phase through the partition coefficient $K_{\mathrm{d}}$ :

$C_{\mathrm{s}}=C_{\mathrm{w}} \cdot K_{\mathrm{d}}$

Hence, replacing Eqs. (8)-(10) into Eq. (7), the total mass $M_{\text {tot }}$ can be expressed as:

$M_{\mathrm{tot}}=M_{\mathrm{w}}+M_{\mathrm{s}}=V \cdot C_{\mathrm{w}} \cdot\left[\theta_{\mathrm{e}}+\rho_{\mathrm{s}} \cdot K_{\mathrm{d}} \cdot\left(1-\theta_{\mathrm{e}}\right)\right]$

The time needed to achieve complete source depletion $t_{\mathrm{d}}$, can be calculated by imposing the condition that the mass transported by groundwater flow $M_{\text {transp }}$, is equal to the total mass initially present $M_{\text {tot }}$ :

$M_{\text {transp }}=M_{\text {tot }}$

Making the simplifying but conservative assumption that the groundwater flow does not affect the constant source concentration during the run-off process, the transported mass can be defined as:

$M_{\text {transp }}=t \cdot Q \cdot C_{\mathrm{W}}$

Replacing Eq. (13) into Eq. (12) and properly manipulating Eq. (13), it is then possible to evaluate the time required for the complete source depletion $t_{\mathrm{d}}$ :

$t_{\mathrm{d}}=\frac{M_{\mathrm{tot}}}{Q \cdot C_{\mathrm{w}}}$

In the framework of the risk analysis approach, this time can be considered as the effective exposure duration $\mathrm{ED}_{\text {eff }}$.

Making reference to the conceptual model reported in Fig. 1, the terms of the latter equation can be expressed as:

$Q=U_{\mathrm{gw}} \cdot S_{\mathrm{w}} \cdot S_{\mathrm{d}}$

$U_{\mathrm{gw}}=K_{\mathrm{s}} \cdot i$

$V=W_{\mathrm{gw}} \cdot S_{\mathrm{W}} \cdot S_{\mathrm{d}}$

Replacing Eqs. (15)-(17) in Eq. (14), the following equation for the estimation of average exposure duration is obtained:

$\mathrm{ED}_{\mathrm{eff}}=\frac{W_{\mathrm{gw}} \cdot\left[\theta_{\mathrm{e}}+\rho_{\mathrm{s}} \cdot K_{\mathrm{d}} \cdot\left(1-\theta_{\mathrm{e}}\right)\right]}{K_{\mathrm{s}} \cdot i}$

It is worth noting that in this model the average exposure duration does not depend on the initial source concentration but only on the hydro-geological characteristics and on the contaminant's properties.

Thus, the proposed approach for the estimation of the effective exposure duration can be summarized as follows. The exposure 
duration is the minimum value between the one provided by Eq. (18) and the one set by the RBCA approach, i.e.:

$$
\left\{\begin{array}{cl}
\mathrm{ED}=\mathrm{ED}_{\mathrm{eff}} & \text { when } \mathrm{ED}_{\mathrm{eff}}<25 \text { years } \\
\mathrm{ED}=25 \text { years } & \text { when } \mathrm{ED}_{\mathrm{eff}} \geq 25 \text { years }
\end{array}\right.
$$

It is worth noting that the value provided by this model does not match the actual time required for the source depletion, but it is rather an hypothetical period of exposure obtained assuming the source concentration constant until complete depletion.

\subsubsection{Source-Depletion model}

Differently from the assumption made in the model discussed above, the source concentration actually decreases with time, thus also affecting the rate of the run-off process and consequently the time to achieve complete source depletion.

The change of total source mass $\mathrm{d} M$ can be calculated differentiating Eq. (11):

$\mathrm{d} M=V \cdot\left[\theta_{\mathrm{e}}+\rho_{\mathrm{s}} \cdot K_{\mathrm{d}} \cdot\left(1-\theta_{\mathrm{e}}\right)\right] \cdot \mathrm{d} C$

As seen before, the time needed to achieve complete source depletion $t_{\mathrm{d}}$, corresponds to the condition that the transported mass is equal to the total mass initially present (Eq.(12)). In this case the effective transported mass can be expressed by differentiating Eq. (13):

$M_{\text {transp }}=Q \cdot C_{\mathrm{w}}(t) \cdot \mathrm{d} t$

Equating Eqs. (20) and (21) provides:

$Q \cdot C_{\mathrm{w}}(t) \cdot \mathrm{d} t=V \cdot\left[\theta_{\mathrm{e}}+\rho_{\mathrm{s}} \cdot K_{\mathrm{d}} \cdot\left(1-\theta_{\mathrm{e}}\right)\right] \cdot \mathrm{d} C$

This differential equation can be manipulated and integrated assuming $C_{\mathrm{W}}=C_{0}$ at $t=0$ :

$-\int_{C_{0}}^{C_{\mathrm{w}}(t)} \frac{\mathrm{d} C}{C_{\mathrm{w}}(t)}=\frac{Q}{V \cdot \theta_{\mathrm{e}}+V \cdot \rho_{\mathrm{s}} \cdot K_{\mathrm{d}} \cdot\left(1-\theta_{\mathrm{e}}\right)} \cdot \int_{0}^{t} \mathrm{~d} t$

Whose solution is:

$\ln \left(\frac{C_{\mathrm{w}}(t)}{C_{0}}\right)=\frac{-Q \cdot t}{V \cdot \theta_{\mathrm{e}}+V \cdot \rho_{\mathrm{s}} \cdot K_{\mathrm{d}} \cdot\left(1-\theta_{\mathrm{e}}\right)}$

Then solving Eq. (24) for the concentration in dissolved phase $C_{\mathrm{w}}(t)$ and replacing the equation parameters given in Eqs. (15)-(17), the source concentration at time $t, C_{\mathrm{w}}(t)$ is given by:

$C_{\mathrm{w}}(t)=C_{0} \cdot \exp \left[\frac{-K_{\mathrm{s}} \cdot i \cdot t}{\theta_{\mathrm{e}} \cdot W_{\mathrm{gw}}+\rho_{\mathrm{s}} \cdot W_{\mathrm{gw}} \cdot K_{\mathrm{d}} \cdot\left(1-\theta_{\mathrm{e}}\right)}\right]$

This equation is equal to the following one, provided by RBCA ToolKit:

$C_{\mathrm{w}}(t)=C_{0} \cdot \exp (-\gamma \cdot t)$

provided that $\gamma$ is equal to:

$\gamma=Q \cdot(A+B)$

with $A$ defined as:

$A=\frac{1}{\theta_{\mathrm{e}} \cdot W_{\mathrm{gw}}+\rho_{\mathrm{s}} \cdot W_{\mathrm{gw}} \cdot K_{\mathrm{d}} \cdot\left(1-\theta_{\mathrm{e}}\right)}$

and assuming $B=0$, i.e. neglecting biodegradation.

It is worth pointing out that in the RBCA ToolKit formulation the groundwater concentration and the initial mass of contaminant are both required as user input. In our model, the mass of contaminant is calculated as a function of the groundwater concentration, always assuming linear equilibrium between the liquid and the soil phase, allowing to provide only the groundwater concentration as user input.

Finally, it is worth to underline that the two analytical models discussed in this section correspond to two limiting ideal models that can be used to describe mass transport in porous media: the Source-Depletion model corresponds to a plug flow model, whereas the Exposure-Duration model to a perfectly well mixed one.

\subsection{Numerical model}

The FEFLOW software (Finite Element subsurface FLOW) version $5.3 \mathrm{x}$ was used in this work. This version allows to simulate 2D and 3D fluid flow, mass and heat transport problems in a saturated media, in unsaturated media and also in variable saturation media [28]. In this work the simulations were performed using the following main settings:

- two dimensional modelling;

- triangular discretization (Tmesh method);

- saturated media (groundwater);

- transient conditions (flow and transport);

- automatic time stepping schemes based on forward Euler/backward Euler method;

- no heat transport;

- Dirichlet (1st kind) and Neumann (2nd kind) boundary conditions.

The point of exposure was positioned at the downstream border of the source-area (see Fig. 1). The calculated concentration values at different times were then used for the cumulative risk calculation as reported in the next section.

The input parameters used for the Feflow simulations are reported in Table 1.

\subsection{Risk calculation}

Risk was calculated using Eq. (2) for the Exposure-Duration model and the ASTM-RBCA approach. In the latter one, exposure duration, ED, was set equal to 25 years, whereas in the former one, ED was set equal to the time required for source depletion, given by Eq. (18). When the numerical and Source-Depletion models were used, the risk was calculated by dividing the whole exposure period in a given number of exposure intervals. For each interval the average concentration at point of exposure and the corresponding incremental risk were calculated. Thus the total risk, $R_{\mathrm{T}}$, was calculated as the sum of the incremental risk values associated to each exposure interval:

$R_{\mathrm{T}}=\sum_{i=1}^{n} R_{i}$

where $R_{i}$ is the risk calculated to a generic $i$ th time interval, calculated using Eq. (2) and with ED equal to the duration of the time interval itself:

$R_{i}=\mathrm{SF} \cdot \frac{\mathrm{CR} \cdot \mathrm{EF}}{\mathrm{BW} \cdot \mathrm{AT}} \cdot \sum C_{\mathrm{poe}, i} \cdot \mathrm{ED}_{i}$

\subsection{Input parameters}

Application of both analytical and numerical models was carried out using the default values for all the input parameters provided in the APAT document [33]. All properties related to the site and contamination source were taken from this reference as well as the soil physical properties (Table 1). Benzene was considered as target pollutant with a representative concentration equal to $0.1 \mathrm{mg} / \mathrm{L}$ in groundwater, which correspond to a value 100 times higher than the current target value set by the Italian legislation [34]. All exposure parameters were taken for industrial/commercial scenario. 
Table 1

Input parameters.

\begin{tabular}{|c|c|c|c|c|c|}
\hline Symbol & Parameter & Units & Sand & Loam & Clay \\
\hline$i$ & Groundwater gradient & $\mathrm{m} / \mathrm{m}$ & 0.01 & 0.01 & 0.01 \\
\hline$W_{\mathrm{gw}}$ & Length of source-zone area & $\mathrm{m}$ & 45 & 45 & 45 \\
\hline$\rho_{\mathrm{s}}$ & Bulk density & $\mathrm{g} / \mathrm{cm}^{3}$ & 1.7 & 1.7 & 1.7 \\
\hline$K_{\mathrm{s}}$ & Saturated hydraulic conductivity & $\mathrm{cm} / \mathrm{s}$ & $8.25 \mathrm{E}-03$ & $2.89 \mathrm{E}-04$ & $5.65 \mathrm{E}-05$ \\
\hline$\theta_{\mathrm{e}}$ & Soil porosity & $\mathrm{cm}^{3} / \mathrm{cm}^{3}$ & 0.385 & 0.352 & 0.312 \\
\hline$f_{\mathrm{oc}}$ & Mass fraction of organic carbon & $\mathrm{g} / \mathrm{g}$ & 0.001 & 0.001 & 0.001 \\
\hline$K_{\mathrm{oc}}$ & Organic carbon/water partition coefficient & $\mathrm{mL} / \mathrm{g}$ & 62 & 62 & 62 \\
\hline$K_{\mathrm{d}}$ & Soil/water partitioning coefficient ${ }^{\mathrm{a}}$ & $\mathrm{mL} / \mathrm{g}$ & 0.062 & 0.062 & 0.062 \\
\hline$C_{0}$ & Initial concentration & $\mathrm{mg} / \mathrm{L}$ & 0.1 & 0.1 & 0.1 \\
\hline
\end{tabular}

a Soil/water partitioning coefficient: $K_{\mathrm{d}}=K_{\mathrm{oc}} \cdot f_{\mathrm{oc}}$.

\section{Results and discussions}

The results reported in this section provide the values of source concentration and carcinogenic risk from contaminated groundwater ingestion, obtained by applying both the numerical and analytical models, described above.

\subsection{Concentration profiles}

Fig. 2 reports the time profile of benzene concentration at the source-area for three different soils (sand, loam and clay) obtained applying the ASTM-RBCA, the Exposure-Duration model, the Source-Depletion model and the numerical model discussed above. The results of the latter model refer to the concentration calculated at a position corresponding to the outlet section of the contamination source, assuming its initial geometry. This allows a fair comparison with the result of the Source-Depletion model, which is based on a plug flow approximation. The ExposureDuration model and the Source-Depletion model do not account for the longitudinal and transverse dispersion during contaminant's migration. For this reason the results obtained by the application of these models have been compared with the FEFLOW results assuming:
- contaminant's migration with low dispersion $\left(a_{x}=a_{y}=a_{z}=0.1 \mathrm{~m}\right)$

- contaminant's migration with dispersion $\left(a_{x}=10 \mathrm{~m} ; a_{y}=a_{z}=1 \mathrm{~m}\right)$

where $a_{x}$ is the longitudinal dispersivity, and $a_{y}$ and $a_{z}$ are the transverse and vertical dispersivities, respectively.

As shown in Fig. 2, the time required for source depletion increases from sandy to clay texture, for all approaches used. For instance, the ED calculated by the Exposure-Duration model increases from 1 year for sandy soil to 20 years for loamy soils and exceeds 25 years for clay soils.

Making reference to the case of sandy soils, reported in Fig. 2, it can be noticed that, using the Exposure-Duration model, the time required for source depletion assuming constant source concentration, would result equal to approximately 1 year, that is much less than the 25 years default exposure duration. The result provided by the Source-Depletion model is somehow in between, with a source depletion time of approximately 3 years, although in this approach the source concentration is not constant but decreases with time. This result is in quite good agreement with the one provided by the numerical model. Similar results are obviously obtained for the other soil textures, although with different time scales. Nevertheless, given the different nature of the proposed models, i.e. steady state for the Exposure-Duration and ASTM-RBCA ones and transient for the numerical and Source-Depletion ones, a fair comparison can
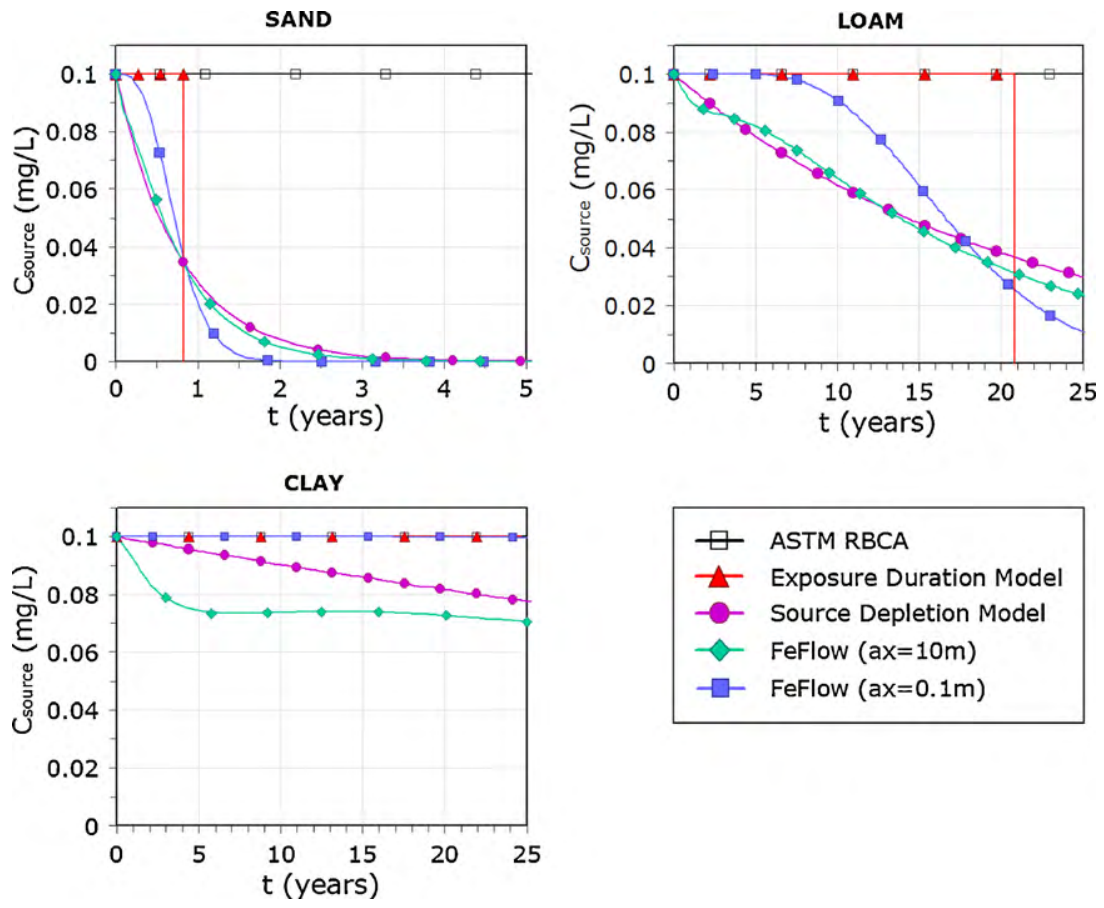

Fig. 2. Benzene source concentration $\left(C_{\text {source }}\right)$ vs. time $(t)$ 
(a)

SAND

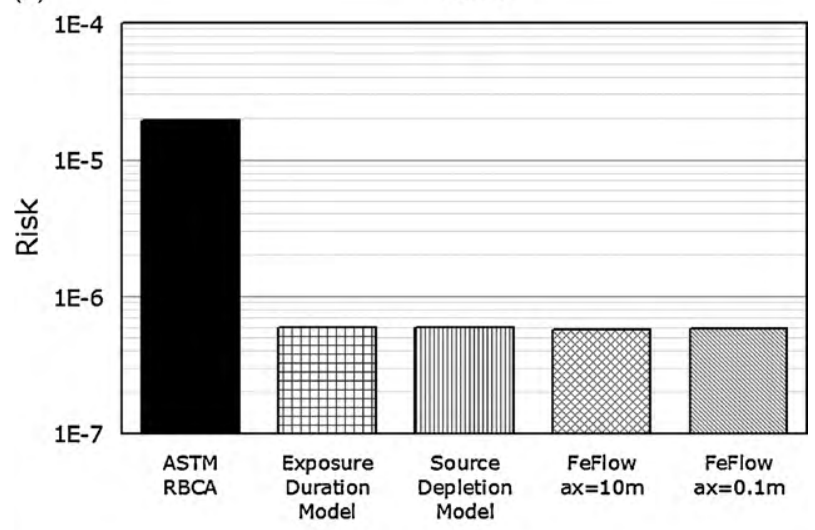

(b)

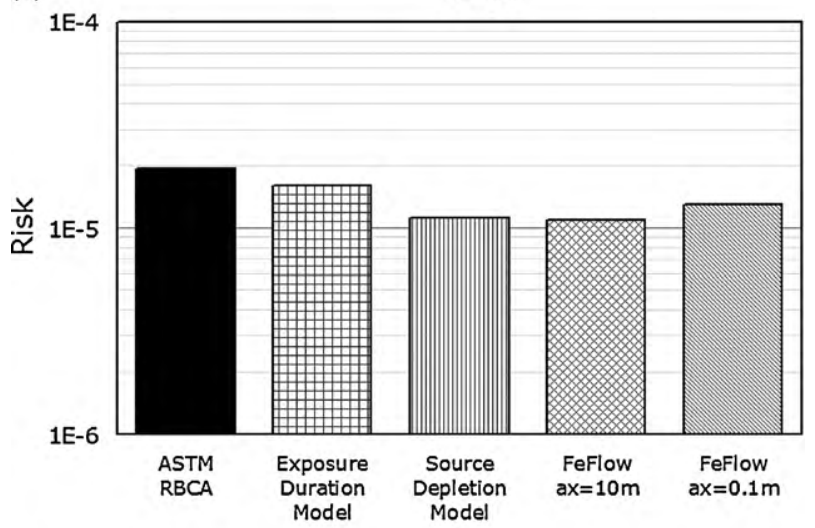

(c)

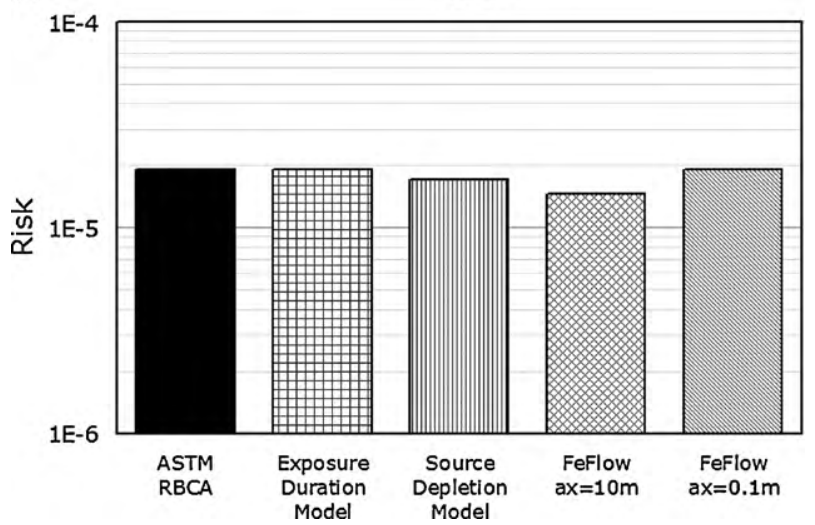

Fig. 3. Carcinogenic risk associated to ingestion of benzene-contaminated groundwater: (a) soil: sand, (b) soil: loam and (c) soil: clay.

be done more correctly in terms of exposure and therefore of risk, and is reported in the next section.

\subsection{Risk calculation}

Risk values obtained for the three investigated soil textures, using the different modelling approaches are reported in Fig. 3. The comparison shows that for permeable soil (e.g. Sand; see Fig. 3a) the ASTM-RBCA approach provides more conservative carcinogenic Risk values $\left(R>1 \times 10^{-5}\right)$, two orders of magnitude higher than those obtained applying the Exposure-Duration model $\left(R \approx 6 \times 10^{-7}\right)$. Looking at Fig. 3a it can be noticed that the results of the Exposure-Duration model are in this case similar to those provided by the Source-Depletion model and slightly more conser-
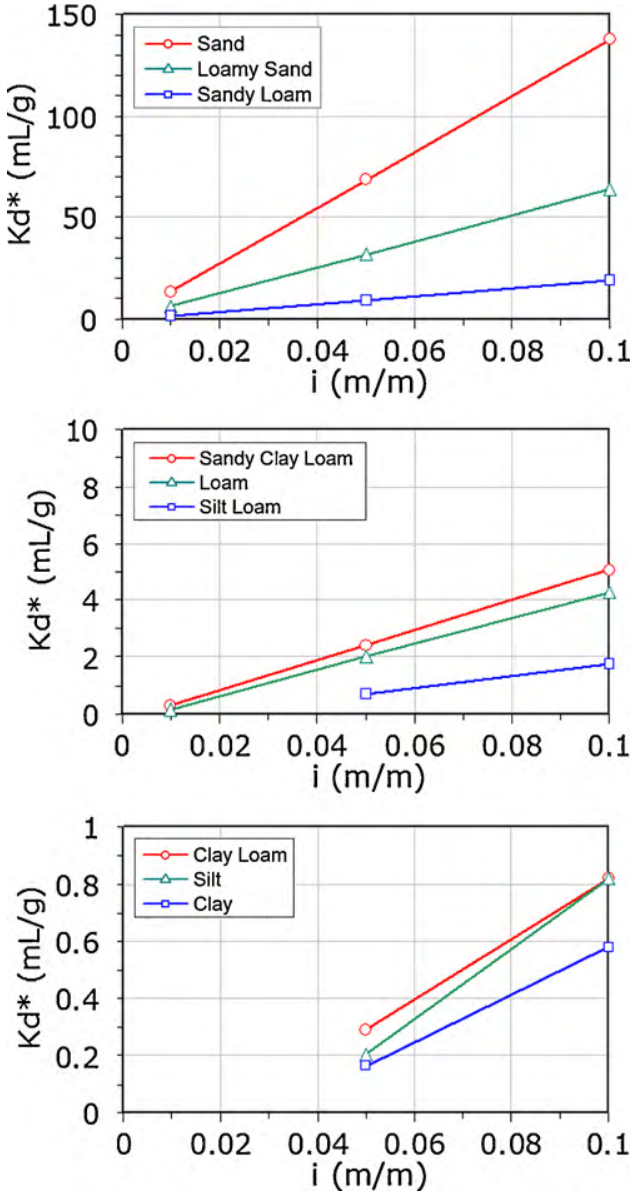

Fig. 4. Limit soil/water partition coefficient $\left(K_{\mathrm{d}}{ }^{*}\right)$ vs. groundwater gradient $(i)$.

vative than those given by the Feflow simulations. The difference between the proposed model and the ASTM-RBCA one, is reduced when a loamy soil is considered (Fig. 3b) whereas the two models provide identical results in the case of a clay soil (Fig. 3c). These results are in agreement with the calculated depletion time (see Fig. 2), which increases, as seen before, from a sandy to a clay soil. This means that, at least in the case of benzene, using the standard ASTM-RBCA approach would lead to an important overestimation of the calculated risk for sandy soils, a lower one for loamy ones and more realistic result for clay soils.

This suggests that the proposed models provide a more realistic picture of the risk condition with respect to the ASTM-RBCA approach, but still more conservative than the one given by a numerical model, although most of the intrinsic simplicity of the ASTM-RBCA approach is maintained, especially as far as the analytical model is concerned.

\subsection{Limits of validity of the Exposure-Duration model}

In view of the results shown above it can be stated that the proposed Exposure-Duration model (easier to apply than the Source-Depletion one), can be used to account for the depletion of the concentration source, although assuming no NAPL is present and respecting the feature of Tier 2 risk analysis models, i.e. using analytical equations.

As previously described, the exposure duration is given by Eq. (19); this means that if the depletion time is lower than the default exposure duration (25 years for industrial receptors), it will be equal to the effective exposure duration, $\mathrm{ED}_{\mathrm{eff}}$, given by Eq. (18). In this case, $\mathrm{ED}_{\mathrm{eff}}$ is a function of both the constituent properties, 
(a)
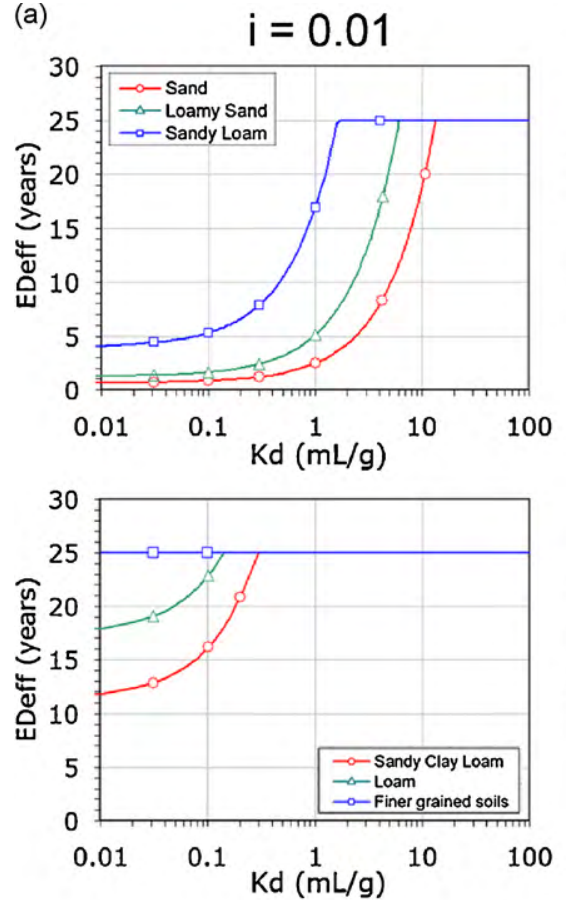

(b)
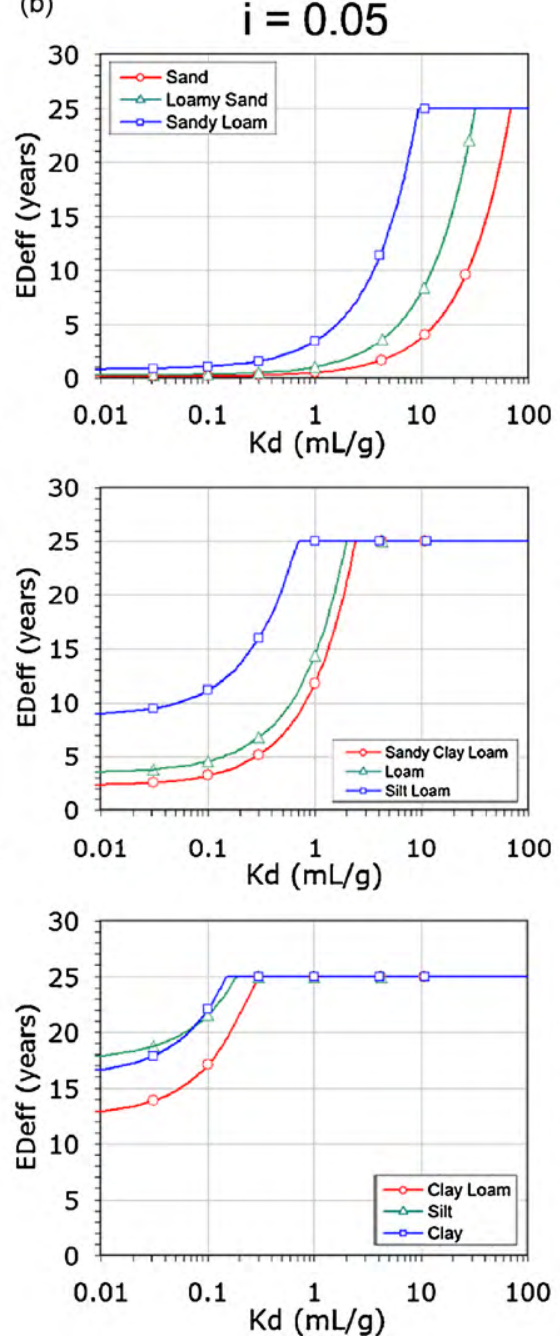

(c)
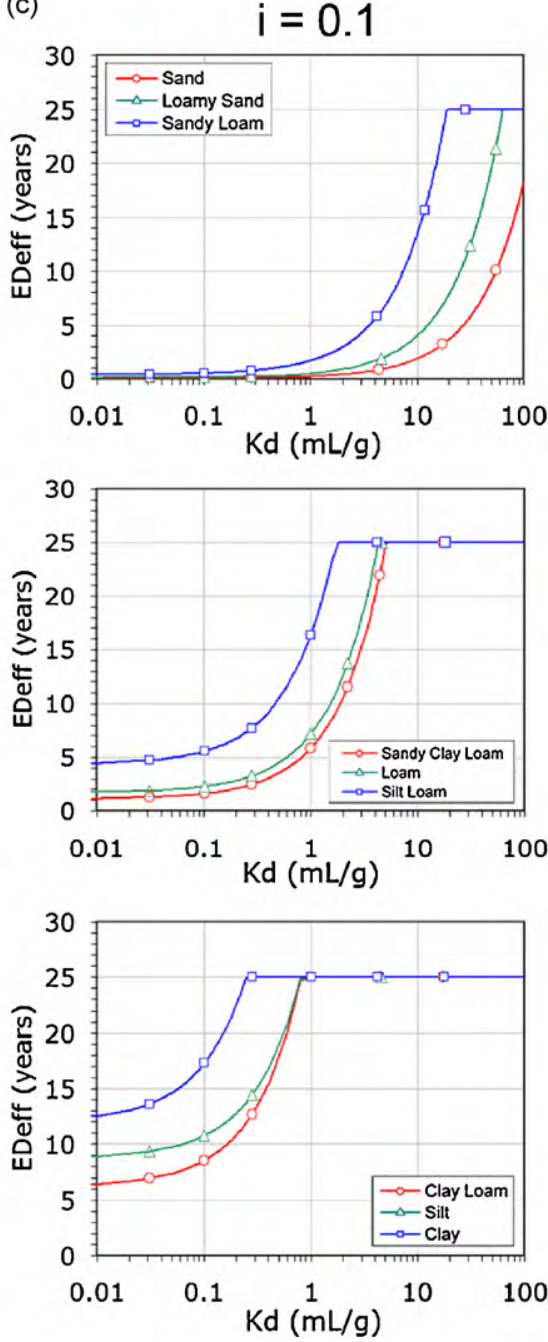

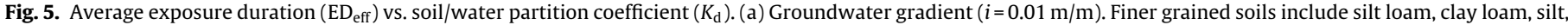
clay. (b) Groundwater gradient ( $i=0.05 \mathrm{~m} / \mathrm{m})$. (c) Groundwater gradient $(i=0.1 \mathrm{~m} / \mathrm{m})$.

through the partition coefficient, $K_{\mathrm{d}}$, and the media characteristics, through the hydrological parameters $K_{\mathrm{s}}, i, \theta_{\mathrm{e}}$ and $\rho_{\mathrm{s}}$. This suggests that the exposure duration for a given soil type is limited by the source depletion time, depending on the value of the partition coefficient $K_{\mathrm{d}}$ and that of the hydraulic gradient, $i$. In other words, for any soil type characterized by a given value of $K_{\mathrm{s}}, \theta_{\mathrm{e}}$ and $\rho_{\mathrm{s}}$, there exists a maximum value of the partition coefficient $K_{\mathrm{d}}{ }^{*}$ will exist below which the condition $\mathrm{ED}_{\mathrm{eff}}<\mathrm{ED}$ holds true and therefore the Exposure-Duration model application can be suggested. Fig. 4 reports these $K_{\mathrm{d}}{ }^{*}$ values for different soil types, as a function of hydraulic gradient. Looking at this figure, it can be noticed that the $K_{\mathrm{d}}{ }^{*}$ value at constant hydraulic gradient, $i$, decreases going from coarse soils to more fine grained ones. For known media properties, Fig. 4 can be used to evaluate if the partition coefficient of a given constituent falls above or below the relevant $K_{\mathrm{d}}{ }^{*}$ value, and thus if the proposed model deserves to be applied for a more correct and realistic evaluation of the exposure duration.

Such a comparison is made more clear looking at Fig. 5, where the effective exposure duration is reported for different soil textures and hydraulic gradient values, as a function of the contaminant partition coefficient $K_{\mathrm{d}}$. Let us consider the case of benzene characterized by a $K_{\mathrm{d}}$ value of $0.062 \mathrm{~mL} / \mathrm{g}$ (assuming a mass fraction of organic carbon of $0.001 \mathrm{~g} / \mathrm{g}$ ). For a groundwater flow with $i=0.01$, Fig. 5a shows that the effective exposure duration, $E D_{\text {eff }}$, is of few years for sandy to sandy loam soils, 14 years for a Sandy clay loam, 21 years for a Loamy soil and the full default exposure duration of 25 years just for finer grained soils. Increasing the hydraulic gradient to 0.05 and 0.1 (Fig. $5 \mathrm{~b}$ and C, respectively), $\mathrm{ED}_{\text {eff }}$, for all soil types will be even lower, once again below the default

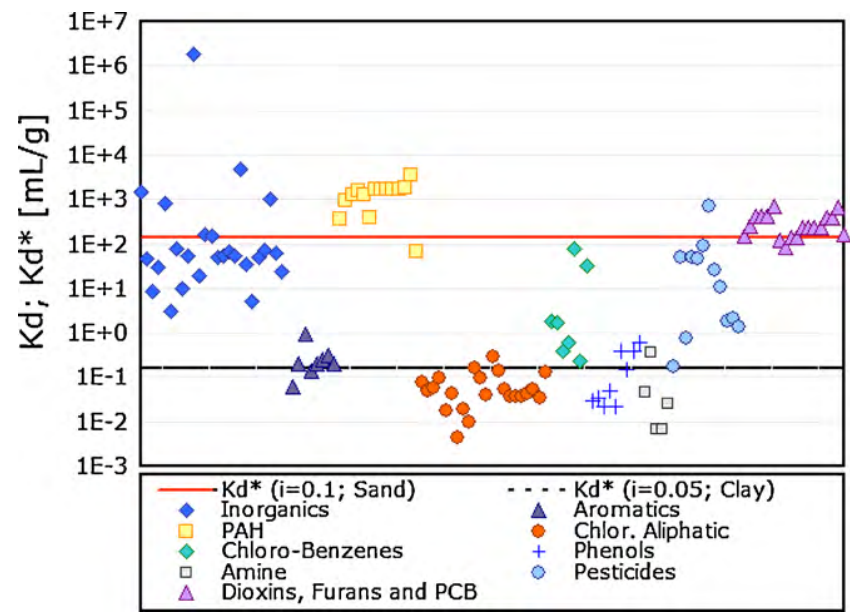

Fig. 6. Limit soil/water partition coefficient $\left(K_{\mathrm{d}}{ }^{*}\right)$ vs. soil/water partition coefficient $\left(K_{\mathrm{d}}\right)$. 
ED. In all these cases, the Exposure-Duration model is useful to get a more physically sound description of the effective exposure time. Application of this model would be useful for all contaminants that are characterized by a partition coefficient value $K_{\mathrm{d}}$, lower than the corresponding $K_{\mathrm{d}}{ }^{*}$, which depends on the hydrogeological site-specific characteristics. Fig. 6 compares the $K_{\mathrm{d}}$ data of the main contaminants, with the $K_{\mathrm{d}}{ }^{*}$ values for two limiting hydro-geological conditions, corresponding on the one hand to a sandy soil with $i=0.1$ and on the other hand to a clay soil with $i=0.05$. It is worth noting that for a sandy soil the $K_{\mathrm{d}}{ }^{*}$ is higher than the partition coefficients of most contaminants, suggesting that neglecting the use of the Exposure-Duration model would lead, to an overestimation of the actual exposure duration and therefore of the human health risk. On the other hand, in the case of the clay soil, the importance of the proposed model would be limited to just few contaminants classes, such as the chlorinated aliphatics, phenols and amines, characterized by higher mobility in groundwater system.

\section{Conclusions}

The present work was focused on the approach provided for on-site receptors exposed to contaminated groundwater. The approach reported in the ASTM-RBCA standard does not take into account the source depletion due to constituent migration in the saturated zone, but assumes that the receptors are exposed to a constant concentration for the entire exposure duration. The comparison with the output of the numerical model FEFLOW showed that this assumption may lead, for some types of constituents and soils, to extremely conservative results in terms of risk. For this reason, in this work alternative modelling approaches, accounting for source depletion were analyzed and discussed. In view of the results obtained by the comparison of these models, the proposed Exposure-Duration model has provided more realistic results with respect to the ASTM-RBCA approach and is easier to apply and slightly more conservative than the RBCA ToolKit and the numerical one. Our suggestion is that this modelling approach may represent a simple but meaningful integration of the ASTM-RBCA one, since it keeps its original simplicity, but allows to overcome its limitations in correctly managing risk for specific site conditions.

\section{References}

[1] API, Risk-Based Methodologies for Evaluating Petroleum Hydrocarbon Impacts, API Publication 4709, 2001.

[2] S.L. Sager, Risk Based Corrective Action (RBCA), Encyclopedia Toxicol. (2005) 733-736.

[3] ASTM, Standard Guide for Risk-Based Corrective Action Applied at Petroleum Release Sites, ASTM, West Conshohocken, PA, 1995, E 1739-95 (Re-approved 2002).

[4] ASTM, Standard Guide for Risk-based Corrective Action, ASTM, West Conshohocken, PA, 2000, E2081-00.

[5] A. Azadpour-Keeley, J.W. Keeley, H.H. Russell, G.W. Sewell, Monitored natural attenuation of contaminants in the subsurface: applications, Ground Water Monit. Remed. 21 (2007) 136-143.
[6] P.C. Johnson, P. Lundegard, Z. Liu, Source zone natural attenuation at petroleum hydrocarbon spill sites. I. Site-specific assessment approach, Ground Water Monit. Remed. 26 (2006) 82-92.

[7] P. Lundegard, P.C. Johnson, Source zone natural attenuation at petroleum hydrocarbon spill sites. II. Application to a former oil field, Ground Water Monit. Remed. 26 (2006) 93-106.

[8] F.I. Khan, T. Husain, Risk-based monitored natural attenuation-a case study, J. Hazard. Mater. B85 (2001) 243-272.

[9] H. Rugner, M. Finkel, A. Kaschl, M. Bittens, Application of monitored natural attenuation in contaminated land management-A review and recommended approach for Europe, Environ. Sci. Policy 9 (2006) 568-576.

[10] U.S.EPA, Monitored Natural Attenuation of Petroleum Hydrocarbons, EPA/600/F-98/021, 1999.

[11] C.N. Mulligan, R.N. Yong, Natural attenuation of contaminated soils, Environ. Int. 30 (2004) 587-601.

[12] T. Shih, Y. Rong, T. Harmon, M. Suffet, Evaluation of the impact of fuel hydrocarbons and oxygenates on groundwater resources, Environ. Sci. Technol. 38 (2004) 42-48.

[13] C.J. Newell, J.A. Connor, Characteristics of Dissolved Petroleum Hydrocarbon Plumes, API, 1998.

[14] H. Prommer, D.A. Barry, G.B. Davis, Modelling of physical and reactive processes during biodegradation of a hydrocarbon plume under transient groundwater flow conditions, J. Contam. Hydrol. 59 (2002) 113-131.

[15] T.H. Christensen, P.L. Bjerg, P. Kjeldsen, Natural attenuation: a feasible approach to remediation of ground water pollution at landfills? Ground Water Monit. Remed. 20 (2000) 69-77.

[16] I.M. Cozzarelli, B.A. Bekins, M.J. Baedecker, G.R. Aiken, R.P. Eganhouse, M.E. Tuccillo, Progression of natural attenuation processes at a crude-oil spill site. I. Geochemical evolution of the plume, J. Contam. Hydrol. 53 (2001) 369-385.

[17] I. Hers, J. Atwater, L. Li, R. Zapf-Gilje, Evaluation of vadose zone biodegradation of BTX vapours, J. Contam. Hydrol. 46 (2000) 233-264.

[18] S. Roggemans, C.L. Bruce, P.C. Johnson, R.L. Johnson, Vadose Zone Natural Attenuation of Hydrocarbon Vapors: An Emperical Assessment of Soil Gas Vertical Profile Data, American Petroleum Institute (API), 2001, No. 15.

[19] P. Hohener, C. Duwig, G. Pasteris, K. Kaufmann, N. Dakhel, H. Harms, Biodegradation of petroleum hydrocarbon vapors: laboratory studies on rates and kinetics in unsaturated alluvial sand, J. Contam. Hydrol. 66 (2003) 93-115.

[20] U.S.EPA, BIOSCREEN-Natural Attenuation Decision Support System. User's Manual Version 1.3, EPA/600/R-96/087, 1996.

[21] U.S.EPA, BIOCHLOR-Natural Attenuation Decision Support System. User's Manual Version 1.0, EPA/600/R-00/008, 2000.

[22] P.A. Domenico, An analytical model for multidimensional transport of a decaying contaminant species, J. Hydrol. 91 (1987) 49-58.

[23] J.A. Connor, R.L. Bowers, T.E. McHugh, A.H. Spexet, Fisher, RBCA ToolKit for Chemical Releases, Ground Water Services Inc., 2007.

[24] L.R. Spence, T. Walden, RISC4-User's Manual, British Petroleum, 2001.

[25] H.S. Rifai, C.J. Newell, J.R. Gonzales, J.T. Wilson, Modeling natural attenuation of fuels with BIOPLUME III, J. Environ. Eng. 126 (2000) 428-438.

[26] A.W. Harbaugh, E.R. Banta, M.C. Hill, M.G. McDonald, MODFLOW-2000, the U.S. Geological Survey modular ground-water model-User guide to modularization concepts and the Ground-Water Flow Process, U.S. Geological Survey (2000), Open-File Report 00-92.

[27] T.P. Clement, A Modular Computer Code for Simulating Reactive Multispecies Transport in 3-Dimensional Groundwater Systems, PNNL-11720, 1997.

[28] WASY, FEFLOW 5.3: User Manual, WASY GmbH Berlin, 2006.

[29] U.S.EPA, Risk Assessment Guidance for Superfund, vol. 1: Human Health Evaluation Manual, Part A, EPA/540/1-89/002, 1989.

[30] L. D'Aprile, E. Scozza, Application of environmental risk analysis at contaminated sites, Ann. Ist. Super. Sanità. 44 (3) (2008) 244-251.

[31] R. Baciocchi, S. Berardi, L. D’Aprile, E. Scozza, I. Verginelli, Validation of transport factors equations in Tier II risk analysis, in: Proceedings of the 10th FKZ/TNO conference on contaminated soils, Milan, 2008.

[32] ASTM, RBCA Fate and Transport Models: Compendium and Selection Guidance, ASTM, West Conshohocken PA, 1999.

[33] APAT (Italian Environmental Protection Agency and Technical Services), Methodological Criteria for Absolute Risk Analysis Application at Contaminated Sites, APAT, 2008, available at: www.isprambiente.it.

[34] Legislative Decree No. 152/06, Environmental Framework Regulation, Italian Official Bulletin No. 88, 2006. 